\title{
Thematic issue: advanced biohydrogen production processes from organic materials
}

\author{
Dai-Viet N. Vo ${ }^{1}$ A. A. Jalii ${ }^{2,3} \cdot$ Sonil Nanda ${ }^{4} \cdot$ Van-Huy Nguyen ${ }^{5}$
}

(c) The Author(s), under exclusive licence to Springer-Verlag GmbH Germany, part of Springer Nature 2021

While fossil fuels remain the primary energy source for industrial production and worldwide transportation, fossil fuel dependency, energy security, and environmental changes induced by excessive usage of crude oil resources remain unsolved global challenges. Substituting petroleumbased energy with an alternative, sustainable and greener fuel is imperative because of increasing fossil fuels exhaustion and climate change. Among emerging renewable energies, hydrogen is lately being considered as an efficient, feasible energy vector and carrier to replace fossil fuels in the coming decades due to its huge energy capacity. Whilst global warming and climate change are provoked by excessive $\mathrm{CO}_{2}$ emissions from fossil fuels combustion, the only by-product released by hydrogen energy consumption is water. Apart from being a standalone fuel, hydrogen can be used in fuel cells and employed as an important precursor in the petrochemical industries for producing synthetic fuels and other vital petrochemicals, viz., fertilizers, green

Dai-Viet N. Vo

vndviet@ntt.edu.vn; vo.nguyen.dai.viet@gmail.com

$\triangle$ A. A. Jalil

aishahaj@utm.my

Sonil Nanda

sonil.nanda@outlook.com

$\triangle$ Van-Huy Nguyen

nvhuy@bdu.edu.vn

1 Institute of Environmental Sciences, Nguyen Tat Thanh University, Ho Chi Minh City 755414, Vietnam

2 School of Chemical and Energy Engineering, Faculty of Engineering, Universiti Teknologi Malaysia, 81310 Johor Bahru, Johor, Malaysia

3 Centre of Hydrogen Energy, Institute of Future Energy, 81310 Johor Bahru, Johor, Malaysia

4 Titan Clean Energy Projects Corporation, Craik, Saskatchewan, Canada

5 Faculty of Biotechnology, Binh Duong University, Thu Dau Mot, Vietnam hydrocarbons, methyl tert-butyl ether (MTBE), alcohols, and dimethyl ether (DME).

Unlike the conventional hydrogen produced from natural gas via catalytic reforming processes, biohydrogen derived from organic materials has gained worldwide interest while being sustainable and carbon-neutral. This thematic issue of Biomass Conversion and Biorefinery highlights the recent progress made to various production technologies for biohydrogen generation. In particular, thermochemical routes, namely steam gasification; sorption-enhanced chemical looping reforming; pyrolysis; catalytic reforming; decomposition technologies using diverse biomasses; agricultural residue wastes; and organic feedstocks will be highlighted in this topical issue. The implementation of other biological techniques including photo-fermentation, sequential dark and photo-fermentation, algal biohydrogen production and microbial fuel cells is also prominently featured-along with nanocatalyst synthesis, kinetic investigation, process optimization and integration, and cutting-edge approaches such as microbial electrolysis cells, microwave and plasma technologies for biohydrogen production.

Lastly, the Guest Editors would like to show appreciation to all contributors worldwide for submitting their outstanding findings for publication in this thematic issue. Additionally, the technical and constructive feedback from reviewers during the peer-review process is highly appreciated. We are also grateful to the guidance from the Editors-in-Chief Prof. Martin Kaltschmitt and Prof. Hermann Hofbauer of Biomass Conversion and Biorefinery and assistance from their editorial office to accomplish this thematic issue.

Publisher's note Springer Nature remains neutral with regard to jurisdictional claims in published maps and institutional affiliations. 